\title{
Research Letter \\ Chlorophyll Detection and Mapping of Shallow Water Impoundments Using Image Spectrometry
}

\author{
Francisco Artigas, ${ }^{1}$ Alex Marti, ${ }^{2}$ Norman Yao, ${ }^{3}$ and Ildiko Pechmann ${ }^{1,4}$ \\ ${ }^{1}$ Meadowlands Environmental Research Institute, New Jersey Meadowlands Commission, 1 DeKorte Park Plaza, \\ Lyndhurst, NJ 07071, USA \\ ${ }^{2}$ Department of Earth and Environmental Sciences, Rutgers University, 249 University Avenue, Newark, NJ 07102, USA \\ ${ }^{3}$ Department of Physics, Harvard University, 9 Oxford Street, Cambridge, MA 02138, USA \\ ${ }^{4}$ Department of Biological Sciences, Rutgers University, 249 University Avenue, Newark, NJ 07102, USA
}

Correspondence should be addressed to Ildiko Pechmann, ildiko.pechmann@njmeadowlands.gov

Received 25 June 2008; Accepted 1 December 2008

Recommended by Patricia Mosto

There exists a common perception that chlorophyll a concentrations in tidal coastal waters are unsuitable to be captured by remote sensing techniques because of high water turbidity. In this study, we use band index measurements to separate active chlorophyll pigments from other constituents in the water. Published single- and multiband spectral indices are used to establish a relationship between algal chlorophyll concentration and reflectance data. We find an index which is suitable to map chlorophyll gradients in the impoundments, ditches, and associated waterways of the Hackensack Meadowlands (NJ, USA). The resulting images clearly depict the spatial distribution of plant pigments and their relationship with the biological conditions of the waters in the estuary. Since these biological conditions are often determined by land usage, the methods in this paper provide a simple tool to address water quality management issues in fragmented urban estuaries.

Copyright (c) 2008 Francisco Artigas et al. This is an open access article distributed under the Creative Commons Attribution License, which permits unrestricted use, distribution, and reproduction in any medium, provided the original work is properly cited.

\section{INTRODUCTION}

Since tidal coastal regions often contain suspended solids and dissolved organic matter which confounds the existence of chlorophyll a (Chl a), there exists a common perception that $\mathrm{Chl}$ a concentrations in such regions are unsuitable to be mapped by remote sensing [1]. Light reflected off a body of water represents a weighted sampling of contributions from water, suspended solids, and chlorophyll [2]. It remains a challenge to develop optical measurements that can separate photons absorbed by active chlorophyll pigments from photons absorbed by other constituents. Currently, available narrow band airborne spectrometers such as Hyperion, AVRIS, AISA, and CASI offer the unique possibility to separate the effects of different constituents using remote sensing techniques [3]. This separation would aid scientists in a variety of ways; indeed, levels of algae, Chl a, and plant pigments have been used as indicators of primary productivity and have been critical to the modeling and understanding of the global carbon cycle [4].
Prior work has focused on identifying portions of the spectrum, which are able to accurately predict the concentrations of various constituents in water. For example, it has been shown that the light absorption of gelbstoff and detritus does not vary greatly and is confined to the blue region of the spectrum; therefore, this absorption can be easily modeled and separated from light absorbed by phytoplankton [5]. The in situ reflectance of different water types has also been measured; for instance, it has been shown that the reflectance ranging from $650-750 \mathrm{~nm}$ is a good predictor of $\mathrm{Chl}$ a $[3,6,7]$. Creating effective spectral indices from reflectance measurements allows for the largescale discrimination of $\mathrm{Chl}$ a concentrations in bodies of water. Although these spectral indices are developed for use with reflectance measurements, in turbid waters, optical signals correlated with $\mathrm{Chl}$ a are often masked by signals from detritus or total suspended solids (TSSs) [8]. It is well documented that in the presence of a strong absorption background, measuring the rate of change of spectra with respect to wavelength amplifies essential details in the spectra 
[9]. In particular, by using various manipulations of first and second derivatives, it is possible to derive expressions which show an excellent correlation with Chl a concentrations in turbid waters $[2,10]$.

The purpose of this study is to test different optical measurements against actual Chl a concentrations from shallow coastal waters by using the derivatives of reflectance. We use our findings to classify Chl a gradients from images captured by aircraft-mounted hyperspectral remote sensors; this allows us to delineate those natural and human forcing functions which affect the biological conditions of water in the estuary.

\section{METHODS}

The study site is located in the New Jersey Meadowlands District along the lower Hackensack River in Lyndhurst, NJ, USA (Supplementary Figure 1 in Supplementary Materials available online at doi:10.1155/2008/146217). The impoundments have tidal influence and at high tide are no more than four to five feet deep. The average salinity in these waters is $5-8 \mathrm{ppm}$, turbidity varies around a baseline reading of 10 FTUs, and TSS averages at around $25 \mathrm{mg} / \mathrm{L}$. A field campaign was conducted to collect reflectance spectra (FieldSpec, Colo, USA Pro Full Range Spectroradiometer from Analytical Spectral Devices) along transects starting at the edge of the impoundment and ending twenty meters inshore with sampling points every two meters. Immediately after each spectral measurement, a half liter water sample was drawn from the first five inches of the surface, where the reflectance measurement had taken place. Samples were stored on ice for 24 hours and analyzed in the laboratory for total Chl a concentration using acetone extraction [11] and for TSS concentration using a gravimetric method [12].

Each component of the spectral reflectance is represented by a different $N$ th order polynomial. Using the Lagrange interpolation polynomial [13], we considered the zero-, first-, and second-order derivatives (curves) for clear water, turbid water, and algal chlorophyll in turbid water. The spectral effects of water reflection are eliminated by the first derivative (first-order effect) [2]. Similarly, spectral effects from turbidity are removed by a second differentiation of the polynomial (second-order effect). Mathematica, V5.2 (Wolfram Research, Oxfordshire, UK, 2006) was used to calculate the first- and second-order derivatives from the raw data using a seven-point numerical differentiation technique derived from the Lagrange interpolation polynomial [2]. Since differentiation tends to enhance the magnitude of noise in the spectra, the Savitzky-Goley algorithm [14] was applied to smooth the data prior to calculating derivatives. To determine the index which best maps our study site, we calculate the coefficients between various indices and Chl a/TSS values for each transect (using SPSS 11.5, III, USA, 2005). The significance of the relationship is determined by using the analysis of variance test (ANOVA). We consider the zero-, first-, and second-order derivatives for the following published indices: R720 (for TSS estimation) and R660-R695 (for Chlorophyll a estimation) from Goodin et al. [2], R680/R670 from Szekielda et al. [7], and

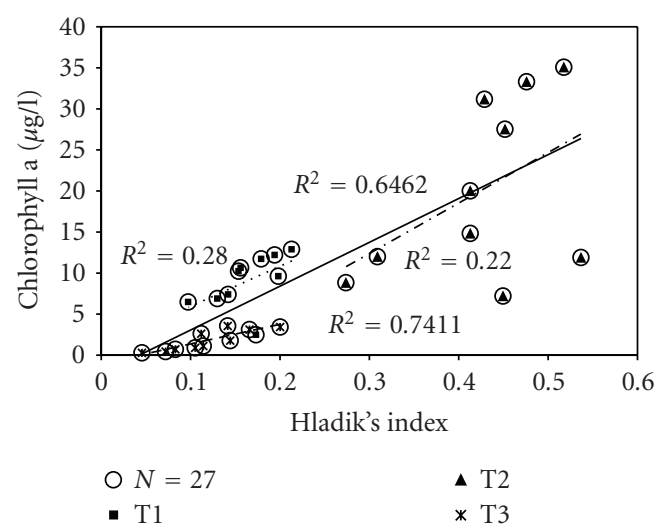

Figure 1: Chlorophyll a concentrations graphed against Hladik's index [15]. The figure depicts the coefficient of correlation for each individual transect (T1, T2, and T3) and for the overall model. The statistical significance of the relationship is calculated using the ANOVA test and details can be found in supplementary Table 1 .

$(\mathrm{AVE}(\mathrm{R} 650+\mathrm{R} 700) \mathrm{R} 675) /(\mathrm{AVE}(\mathrm{R} 440+\mathrm{R} 550))$ from Hladik [15]. Since our spectral measurements started at $450 \mathrm{~nm}$, we modified Hladik's index, replacing the reflectance values at $440 \mathrm{~nm}$ with ones measured at $450 \mathrm{~nm}$.

Hyperspectral imagery of the entire lower Hackensack River (8.288 hectares) was collected on October 5, 2004 using the Airborne Imaging Spectroradiometer for Applications (AISA) [16]. We utilize a mask to select only pixels that are associated with open water; further, we ensure that pixels used to estimate Chl a concentration were free of floating vascular vegetation and did not include areas of exposed mud flats. However, brightness differences between flight lines and shadows remain a significant image-related error. It is our assumption that these errors are associated with flight line direction. Hladik's index, which showed a strong correlation to Chl a concentration for all transects, was selected to create gradient images for the estuary. The index was entered in ENVI's BandMath function which results in a single-band image where each pixel acquires the index value. Finally, trophic state classes were assigned using Chl a concentration as follows: oligotrophic $<2.6 \mu \mathrm{g} / \mathrm{L}$, mesotrophic $2.6-7.3 \mu \mathrm{g} / \mathrm{L}$, eutrophic 7.3-20 $\mu \mathrm{g} / \mathrm{L}$, and hypereutrophic $>20 \mu \mathrm{g} / \mathrm{L}$ [17].

\section{RESULTS AND DISCUSSION}

Chl a concentration along our transects varied from $0.2 \mu \mathrm{g} / \mathrm{L}$ to $35 \mu \mathrm{g} / \mathrm{L}$, similar to what was observed for the fall season in other studies $[18,19]$. According to published trophic scales in the fall season, these waters are oligotrophic or mesotrophic and have low to moderate productivity with intermediate to low clarity [17]. The results of the field study show that TSS remains almost constant $\left(r^{2}<0.4\right)$ along the entire length of the transects, while Chl a concentration increased significantly $\left(r^{2}>0.85 ; P<.05\right)$ from near shore to inshore (see Supplementary Figure 2). Spectra collected from $15 \mathrm{~cm}$ above the water surface display the typical peaks and troughs associated with living plant pigments (see Supplementary Figure 3). 


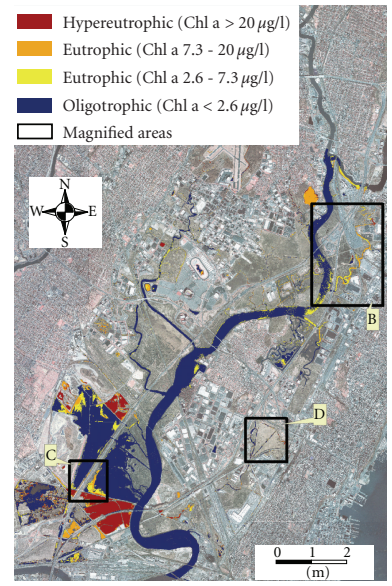

(a)

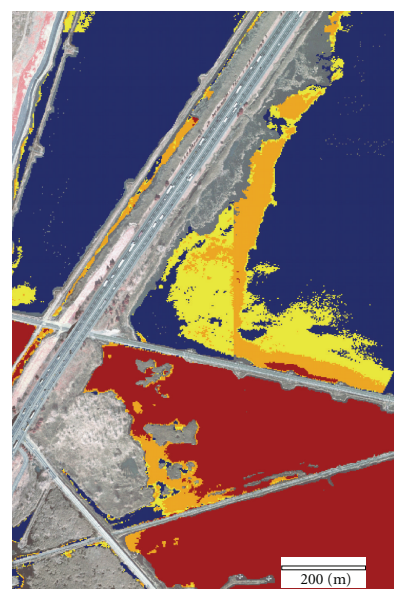

(c)

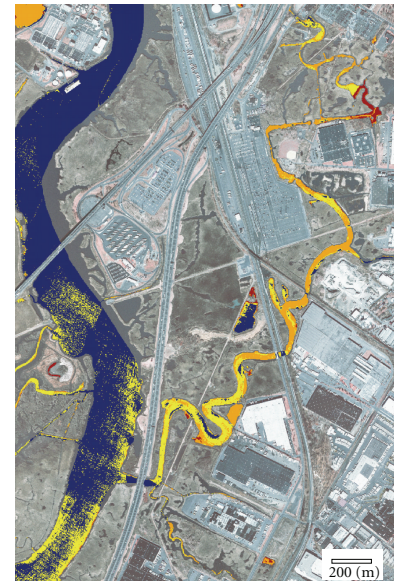

(b)

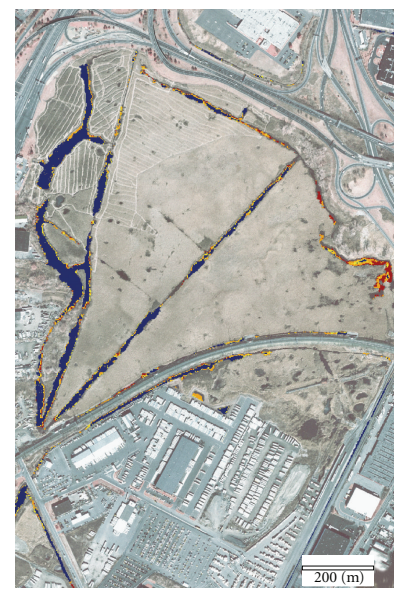

(d)
Figure 2: Open waters of the New Jersey Meadowlands District showing (a) the entire hydrological network of the District, (b) the higher trophic state of tributaries as compared to the main channel, (c) hydraulic connectivity beneath an abandoned railroad line, and (d) stagnant water in a poorly draining ditch network.

The relationship between the indices and water constituents was stronger in the overall model $(N=27$, after removal of three outliers) as compared to each individual transect (Supplementary Table 1). Our field data not only agreed with several band indices from the literature but also conflicted with other published claims. For example, Goodin et al. [2] suggested that the first derivative of R720 may estimate TSS, but our data showed no relationship between the first derivative of R720 and TSS. It is important to note that this is consistent with claims within [2] since the wavelengths chosen by Goodin et al. are for comparison purposes to evaluate the performance of the derivative method. In particular, these wavelengths were not intended to be predictive indicators. On the other hand, our data clearly verified that the index of Szekielda et al. (R680)/(670) is a good estimator of Chl a showing a strong relationship with plant pigment in all transects as well as in the overall model. Additionally, Hladik's index showed a very strong relationship between the raw/first derivative and Chl a concentration; this relationship held true for both individual transects and for the overall model (see Figure 1 Supplementary Table 1).

Based on our field measurement results, Hladik's index was selected for mapping the $\mathrm{Chl}$ a concentration in the District's hydrological network, the results of which are shown in Figure 2. First, we used Hladik's overall model, with $r^{2}=0.853$ to classify all open water pixels. Since this model is not as accurate for concentrations lower than $2.6 \mu \mathrm{g} / \mathrm{L}$, we selected all pixels that were classified by the overall model as having $2.6 \mu \mathrm{g} / \mathrm{L}$ or less of $\mathrm{Chl}$ a and reclassified them using Hladik's T3 index model, with $r^{2}=$ 0.741. Figures $2(\mathrm{a})-2(\mathrm{~d})$ show the results of the Chl a image classification. The entire open water surfaces in the District are shown in Figure 2(a). Tide restricted impoundments to the south west show the greatest productivity; this is in agreement with field observations in these areas which are characterized by chronic algal scum and macrophyte problems. On the other hand, the main channel of the river is mainly oligotrophic with mesotrophic areas to the north, which are connected to eutrophic tributaries that have their origins in urbanized areas. Figure 2(b) presents a tributary showing pockets of hypereutrophic waters along its course. The largest of these pockets to the north is clearly linked to several industrial facilities. As the tributary meanders through wetlands and away from developed sites, it becomes less productive emphasizing the role of wetlands in improving water clarity. It also shows the trophic status increasing upstream as it connects with urban development. The hydraulic connectivity beneath an abandoned railroad connecting a tide-restricted impoundment with hypereutrophic waters to an oligotrophic water body off the main river channel is captured by Figure 2(c). Finally, Figure 2(d) shows a network of ditches and channels holding stagnant waters, which over time become a breeding ground for mosquitoes.

\section{CONCLUSION}

Our results show that there are band indices which effectively capture plant pigment concentrations in highly turbid waters. Additionally, our study depicts the ability, in some cases [7], for the reflectance rate of change expressed through a mathematical derivative to further separate the effects of turbidity from those of $\mathrm{Chl} \mathrm{a}$; this is an essential aspect of mapping turbid waters since it strengthens the index-plant pigment relationship. We find that Hladik's index shows the strongest relationship with $\mathrm{Chl}$ a when all data points $(N=27)$ are taken into account. This index captures the area of variability for light absorption and reflection in the red and NIR; further, the index is normalized with respect to the dissolved organic fraction in the blue segment of the spectra. Our field transects cover a representative chlorophyll range for the entire estuary and regressions result in a highly significant overall model. The resulting images clearly showed $\mathrm{Chl}$ a gradients as represented by the trophic state. Thus, our method allows for an inspection of the Chl a concentration in relation to human land use and provides 
a clear link between the different manmade forcing functions that are driving the biological conditions of the waters in the estuary.

\section{ACKNOWLEDGMENTS}

The technical assistance of Dr. Jian-sheng Yang and Dr. Ruji Yao is gratefully acknowledged. The authors would like to thank Robert Saverino for his editorial work. This project was funded by the Meadowlands Environmental Research Institute and the Herchel Smith Research Fellowship.

\section{REFERENCES}

[1] C. E. Del Castillo, P. G. Coble, R. N. Conmy, F. E. MüllerKarger, L. Vanderbloemen, and G. A. Vargo, "Multispectral in situ measurements of organic matter and chlorophyll fluorescence in seawater: documenting the intrusion of the Mississippi River plume in the West Florida Shelf," Limnology \& Oceanography, vol. 46, no. 7, pp. 1836-1843, 2001.

[2] D. G. Goodin, L. Han, R. N. Fraser, D. C. Rundquist, W. A. Stebbins, and J. F. Schalles, "Analysis of suspended solids in water using remotely sensed high resolution derivative spectra," Photogrammetric Engineering \& Remote Sensing, vol. 59, no. 4, pp. 505-510, 1993.

[3] G. Quibell, "The effect of suspended sediment on reflectance from freshwater algae," International Journal of Remote Sensing, vol. 12, no. 1, pp. 177-182, 1991.

[4] M. J. Behrenfeld and P. G. Falkowski, "A consumer's guide to phytoplankton primary productivity models," Limnology \& Oceanography, vol. 42, no. 7, pp. 1479-1491, 1997.

[5] C. S. Roesler, M. J. Perry, and K. L. Carder, "Modeling in situ phytoplankton absorption from total absorption spectra in productive inland marine waters," Limnology \& Oceanography, vol. 34, no. 8, pp. 1510-1523, 1989.

[6] A. Gitelson, F. Szilagyi, and K.-H. Mittenzwey, "Improving quantitative remote sensing for monitoring of inland water quality," Water Research, vol. 27, no. 7, pp. 1185-1194, 1993.

[7] K.-H. Szekielda, C. Gobler, B. Gross, F. Moshary, and S. Ahmed, "Spectral reflectance measurements of estuarine waters," Ocean Dynamics, vol. 53, no. 2, pp. 98-102, 2003.

[8] T. H. Demetriades-Shah, M. D. Steven, and J. A. Clark, "High resolution derivative spectra in remote sensing," Remote Sensing of Environment, vol. 33, no. 1, pp. 55-64, 1990.

[9] A. E. Martin, "Difference and derivative spectra," Nature, vol. 180, no. 4579, pp. 231-233, 1957.

[10] D. C. Rundquist, L. Han, J. F. Schalles, and J. S. Peake, "Remote measurement of algal chlorophyll in surface waters: the case for the first derivative of reflectance near $690 \mathrm{~nm}$," Photogrammetric Engineering \& Remote Sensing, vol. 62, no. 2, pp. 195-200, 1996.

[11] D. J. Webb, B. K. Burnison, A. M. Trimbee, and E. E. Prepas, "Comparison of chlorophyll $a$ extractions with ethanol and dimethyl sulfoxide/acetone, and a concern about spectrophotometric phaeopigment correction," Canadian Journal of Fisheries and Aquatic Sciences, vol. 49, no. 11, pp. 23312336, 1992.

[12] EPA Method 160.2, "EPA method 160.2 for the analysis of samples for Total Suspended Solids," 2002, http://www.epa .gov/region09/qa/pdfs/160_2.pdf.

[13] S. Barnett and T. M. Cronin, Mathematical Formulae for Engineering and Science Students, Longman, London, UK, 1986.
[14] F. Tsai and W. Philpot, "Derivative analysis of hyperspectral data for detecting spectralfeatures," Geoscience \& Remote Sensing, vol. 3, pp. 1243-1245, 1997.

[15] C. M. Hladik, Close range, hyperspectral remote sensing of Southeastern eustaries and an evaluation of phytoplankton chlorophyll a predictive algorithms, M.S. thesis, Creighton University, Omaha, Neb, USA, 2004.

[16] F. J. Artigas and J. S. Yang, "Hyperspectral remote sensing of marsh species and plant vigour gradient in the New Jersey Meadowlands," International Journal of Remote Sensing, vol. 26, no. 23, pp. 5209-5220, 2005.

[17] R. E. Carlson, "A trophic state index for lakes," Limnology \& Oceanography, vol. 22, no. 2, pp. 361-369, 1977.

[18] USGS, "Natural Water Information System," 1994, http://nwis .waterdata.usgs.gov/nwis.

[19] MERI, "Meadowlands Environmental Research Institute Scientific Data," 2006, http://merigis.njmeadowlands.gov/vdv/ Index.php. 

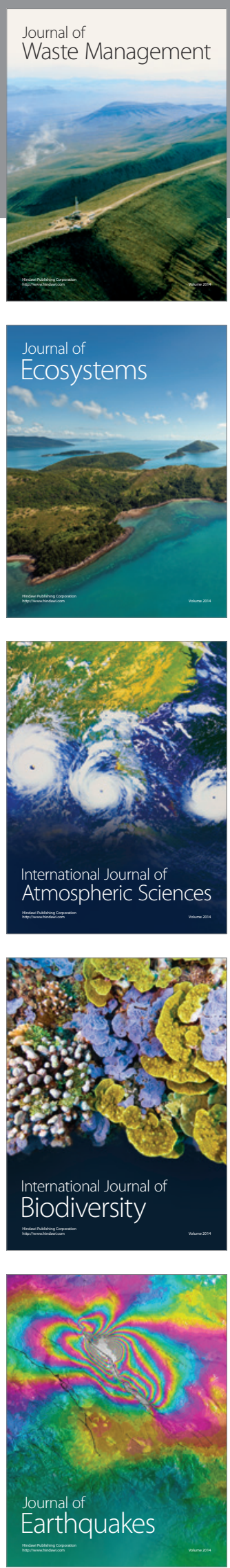
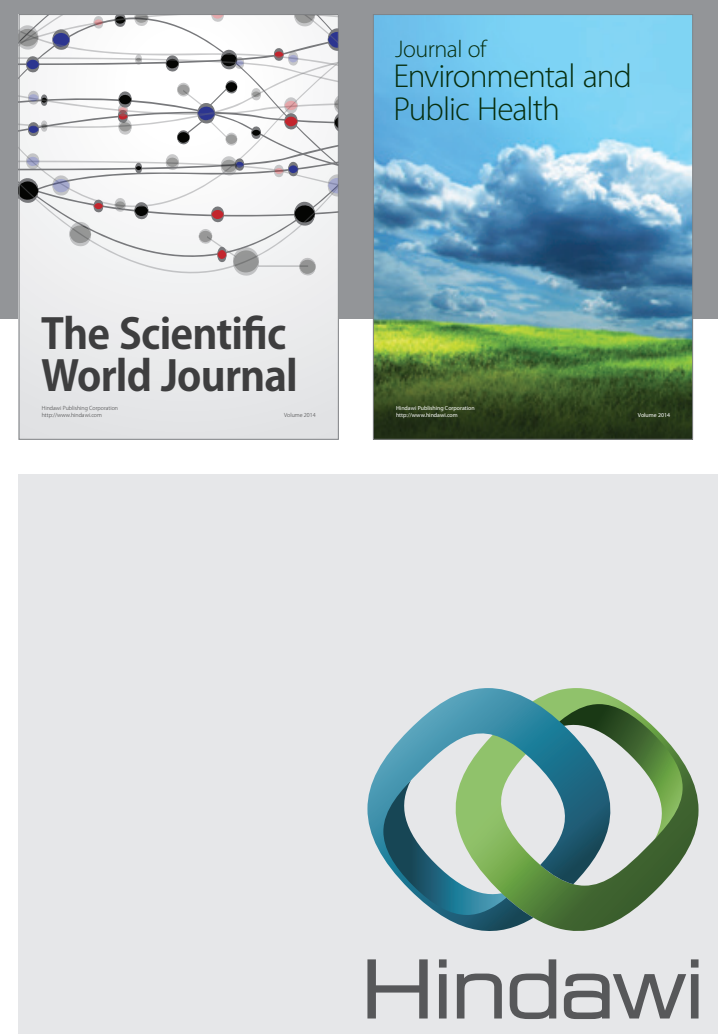

Submit your manuscripts at

http://www.hindawi.com
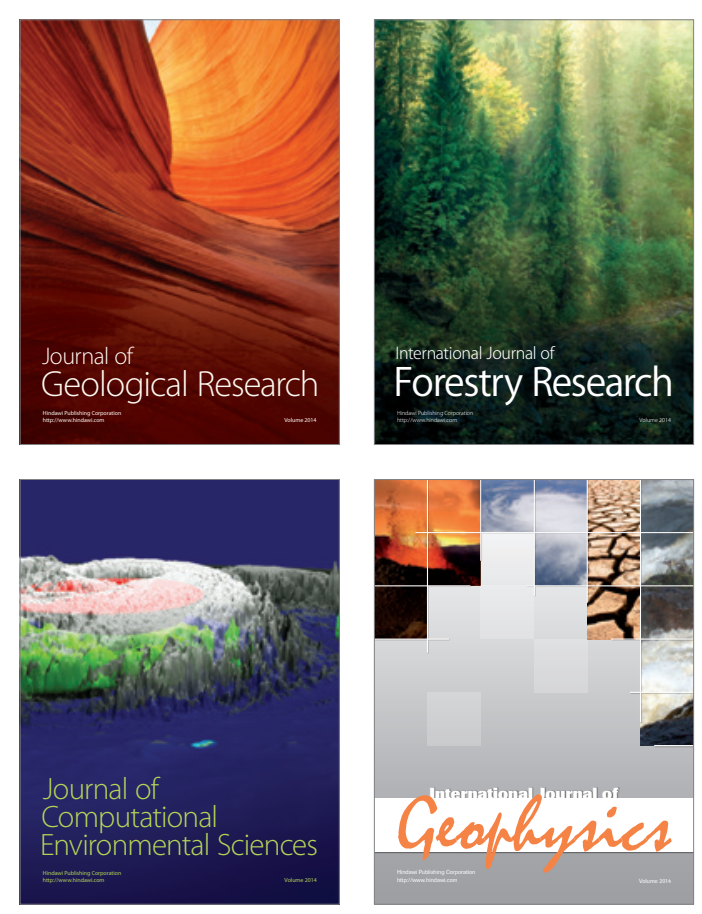
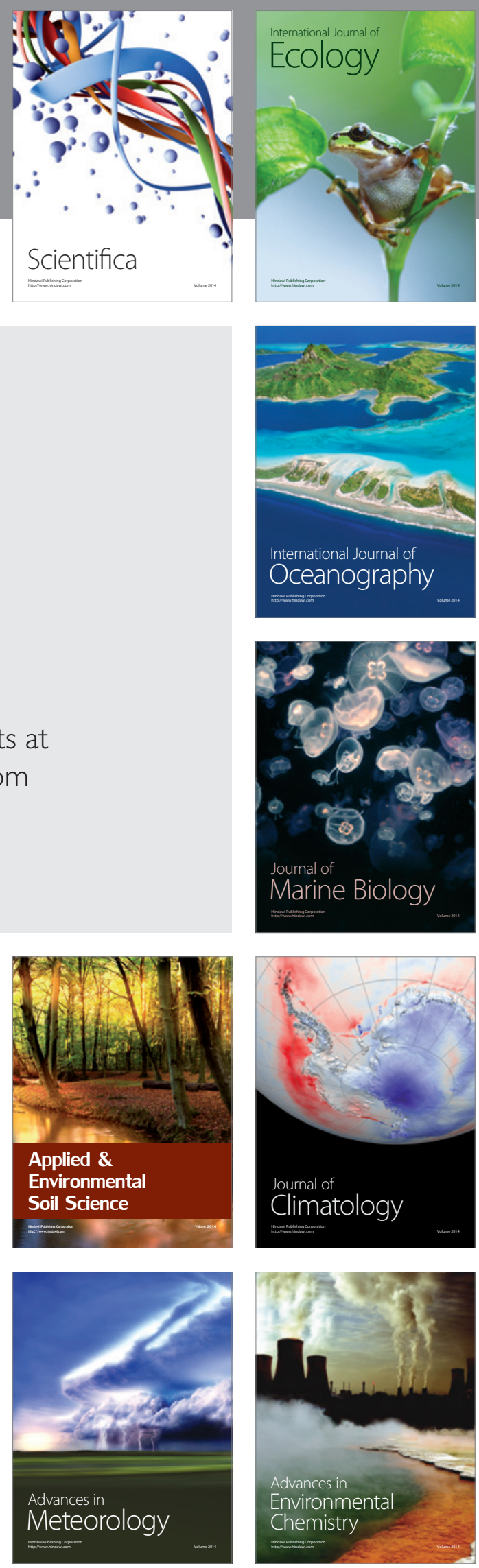